\title{
Analysis of the Inhomogeneous Barrier in In/p-Si Schottky Contact and Modified Richardson Plot
}

\author{
J.M. Dhimmar, H.N. Desai, B.P. Modi* \\ Department of Physics, Veer Narmad South Gujarat University, Surat, Gujarat, India
}

(Received 27 January 2016; revised manuscript received 09 June 2016; published online 21 June 2016)

\begin{abstract}
The current-voltage (I-V) characteristics of In/p-Si Schottky barrier contact were measured over the temperature range $230-360 \mathrm{~K}$ with interval of $10 \mathrm{~K}$. The calculated zero bias barrier height $\left(\phi_{b o}\right)$ and the ideality factor $(n)$ using thermionic theory show strong temperature dependence. The experimental values of $\phi_{b o}$ and $\mathrm{n}$ for $\mathrm{In} / p$-Si Schottky contact range from $0.70 \mathrm{eV}$ and 1.91 (at $360 \mathrm{~K}$ ) to $0.49 \mathrm{eV}$ and 2.99 (at $230 \mathrm{~K}$ ) respectively. The conventional Richardson plot exhibits nonlinearity at lower temperature. The Richardson constant determined from intercept at the ordinate of this experimental linear portion is the value of $2.07 \times 10^{-8} \mathrm{~A} / \mathrm{cm}^{2} \mathrm{~K}^{2}$ which is much lower than the theoretical value $32 \mathrm{~A} / \mathrm{cm}^{2} \mathrm{~K}^{2}$ for holes in $p$-type silicon. The temperature dependence of Schottky barrier characteristics of the contact was interpreted on the basis of the existence of Gaussian distribution of the barrier height around a mean value due to barrier height inhomogeneties prevailing at the metal semiconductor interface. The modified $\ln \left(\frac{I_{s}}{T^{2}}\right)-\left(q^{2} \sigma_{0}^{2} / 2 k^{2} T^{2}\right)$ versus $\frac{1}{T}$ plot gives $\phi_{b o}=1.17 \mathrm{eV}$ and $A^{*}=31.16 \mathrm{~A} / \mathrm{cm}^{2} \mathrm{~K}^{2}$ with standard deviation $\sigma_{0}=0.16 \mathrm{~V}$.
\end{abstract}

Keywords: Zero bias barrier height, Schottky contact, Ideality factor, Modified Richardson plot, Standard deviation.

DOI: 10.21272/jnep.8(2).02006

PACS numbers: 73.30. + y, 73.20. $-\mathrm{r}$

\section{INTRODUCTION}

Metal-Semiconductor (M-S) contacts are found to be important research activity because the knowledge of barrier formation is still far from the complete despite the fact that they are work horse at many electronic applications like surge protection, high speed operation, microwave field effect transistors, radio frequency detectors, temperature sensors and solar cells etc. [1-4]. Although, M-S contacts have been used as research tool in the characterization of new semiconductor materials. In the information era, it is continuing need faster and complex systems to improve in device technology. Usually, the analysis of the characteristics I-V are linear in the semi-logarithmic scale at low voltages, but deviate noticeably from linearity due to the effect of parameters such as the series resistance, the interfacial layer and interface states [6-9]. The series resistance is only effective in the downward-curvature region (non linear region) of the forward I-V characteristics at large applied voltages but ideality factor and barrier height are effective through out the region of characteristics $[10,11]$. This is because that the lining up process of energy bands in M-S junctions after contact are expected to depend on various charge transfer mechanisms, e.g. intrinsic surface states, metal induced gap states, impurities, microstructure defects,, crystallography and relative orientations of atoms at contact and across the interface $[12,13]$. The performance and stability of
Schottky contact especially depend on the formation of insulator between M-S interface, inhomogeneties and series resistance. The analysis of the I-V characteristics of the Schottky contact based on thermionic emission theory typically, reveals an abnormal decrease of zero bias barrier height and increase in the ideality factor with decrease in temperature. [14-21]. The decrease in the barrier height at low temperatures leads to non-linearity in the Richardson's plot, and is found to be non ideal. The theoretical studies based on the effect of a Gaussian distribution of Schottky barrier on the I-V characteristics have been also reported in literature [22-28].

In the present study the forward bias I-V characteristics of In/ $p$-Si Schottky contact were measured over the temperature range of $220-360 \mathrm{~K}$. The temperature dependent Schottky barrier height and ideality factor of the non ideal In/ $p$-Si Schottky contact modified Richardson plot offers a good straight line over the entire temperature range [29]. The resultant temperature dependent non ideal Schottky contacts have been explained on the basis of the existence of a Gaussian distribution of the barrier heights around a mean value due to inhomogeneties at the M-S interface.

\section{EXPERIMENTAL PROCEDURE}

In/ $p$-Si Schottky diode was prepared on a well polished single crystal of silicon having resistivity $(\rho \approx 1 \Omega \cdot \mathrm{cm})$ with (100) orientations. The sample, p-type silicon wafer was ultrasonically degreased by dipping into isopropyl alcohol

\footnotetext{
*bharatpmodi@gmail.com
} 
and washed with de-ionized water. After chemically etched with $4: 1: 3$ solution of $\mathrm{HNO}_{3}: \mathrm{HF}: \mathrm{NH}_{4} \mathrm{OH}$ for $30 \mathrm{sec}$. till brown vapour appeared and then it was dipped for a minute in dilute solution of $1: 9 \mathrm{HF}: \mathrm{H}_{2} \mathrm{O}$ [30]. Finally, the wafer was rinsed in deionized water for $30 \mathrm{sec}$. The thick aluminum back contact (thickness of $3000 \AA$ ) was thermally evaporated by means of a tungsten filament onto the complete back of silicon crystal under pressure $1 \times 10^{-6}$ Torr. The low resistivity ohmic back contact was made by using by an annealing treatment at $550{ }^{\circ} \mathrm{C}$ for 30 minutes in under pressure $1 \times 10^{-6}$ Torr. The Schottky contact was formed onto front polished surface of silicon by evaporation of high purity soft indium metal dots with diameter of about $0.828 \mathrm{~mm}$. The I-V measurements were performed by the use of a Keithly electrometer-614 and a programmable power supply in temperature range of 220-360 K using a temperature controlled cryostat.

\section{RESULTS AND DISCUSSION}

The forward bias I-V characteristics of the In/ $p-\mathrm{Si}$ Schottky contact for wide temperature range of 220$360 \mathrm{~K}$ by step of $10 \mathrm{~K}$ are shown in Fig. 1. The forward current through a Schottky barrier contact at a forward bias $(V \geq 3 \mathrm{kT} / q)$ according to thermionic emission (TE) theory, is given by $[31,32]$

$$
I=I_{s} \exp \left(\frac{q V}{n k T}\right)\left[1-\exp \left(-\frac{q V}{k T}\right)\right]
$$

where $I_{s}$ is the saturation current and is defined by

$$
I_{s}=A A^{*} T^{2} \exp \left(-\frac{q \phi_{b o}}{k T}\right)
$$

Where $A$ is the effective diode area, $A^{*}$ is the Richardson constant for $p$-type $\mathrm{Si}\left(A^{*}=32 \mathrm{~A} \mathrm{~cm}^{-2} \mathrm{~K}^{-2}\right)$, $q$ is the electronic charge, $V$ is the voltage across the diode, $k$ is the Boltzman constant, $T$ is the absolute temperature, $\phi_{b o}$ the zero-bias barrier height and $n$ is the ideality factor. The ideality factor is calculated using the slope of straight line region of the forward bias logarithmic characteristic I-V through relation

$$
n=\frac{q}{k T} \frac{d V}{d(\ln I)}
$$

Where $n$ is justified of conformity of pure thermionic emission. The variation of the experimental ideality factor at different temperatures is plotted in Fig. 2. As shown in the figure, an apparent increase in the ideality factor has been attributed to the effects such as inhomogeneities of thickness, non uniformity of the interfacial charges and insulator layer between metal and semiconductor. These give rise to an extra current such that the over all characteristics still remain consistent with the thermionic emission processes [33].

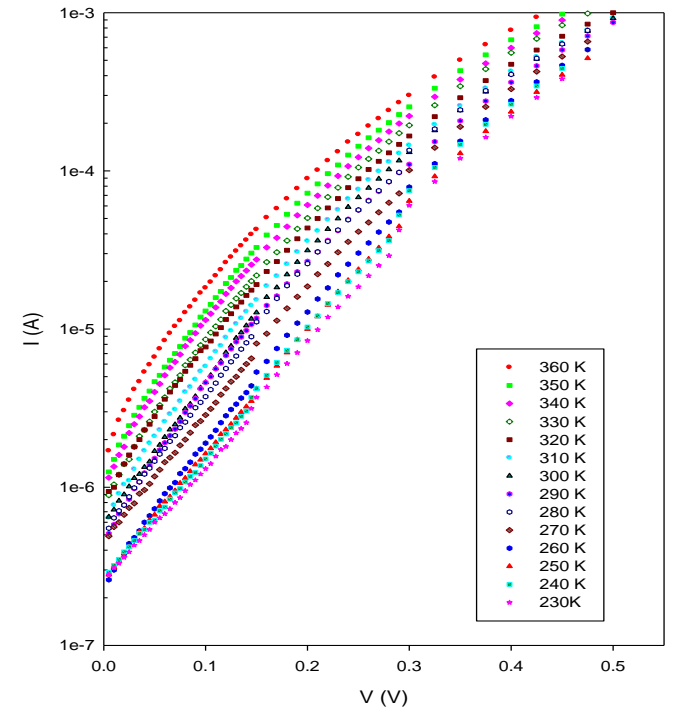

Fig. 1 - The forward I-V characteristics for $\mathrm{In} / p-\mathrm{Si}$ Schottky contact at different temperatures

The value of $I_{S}$ saturation current is determined from the intercept of the plot $\ln I$ versus $V$ in the temperature range of 220-360 K shown in Fig. 1. The calculated value $I s$ is used to determine zero bias barrier height $\phi_{b o}$ is expressed as [31]:

$$
\phi_{b o}=\frac{k T}{q} \ln \left(\frac{A A^{*} T^{2}}{I_{s}}\right)
$$

The barrier height obtained under flat band condition is called the flat barrier height $\phi_{b F}$. Flat band barrier height is considered as the real fundamental quantity since the electric field in the semiconductor is zero under flat condition unlike in the case of zero bias barrier height. Also this eliminates the effect of the image force lowering that would affect the I-V characteristics and removes the influence of lateral inhomogeneity [34-35]. The flat-band barrier height $\phi_{b F}$ is calculating from the experimental ideality factor and zero bias barrier height $\phi_{b o}$ by the following equation [36]:

$$
\phi_{b F}=n \phi_{b o}-(n-1) \frac{k T}{q} \ln \left(\frac{N_{V}}{N_{A}}\right)
$$

Where $N_{V}$ is the effective density of states in the valance band and $N_{A}$ is the carrier concentration of the semiconductor $\left(10^{16} \mathrm{~cm}^{-3}\right)$ used.

The value of zero bias barrier height $\left(\phi_{b o}\right)$ and flat band barrier height $\left(\phi_{b F}\right)$ are plotted as function of temperature in Fig. 3. The plot shows an increasing trend for $\phi_{b o}$ with increasing temperature of Schottky contact depending on the electric field across the contact consequently on the applied bias voltage. As shown in Fig. 3 the temperature 
dependence of the flat band barrier height can be expressed as

$$
\phi_{b F}(T)=\phi_{b F}(T=0)+\alpha T
$$

where $\phi_{b F}$ is the flat band barrier height extrapolated to $T=0 \mathrm{~K}$ and $\alpha$ is its temperature coefficient. In Fig. 3, the fitting of $\phi_{b F}(T)$ data in equation (6) provides $\phi_{b F}(T=0)=1.07 \mathrm{eV}$ and $\alpha=3.130 \times 10^{-4} \mathrm{eV} \mathrm{K}^{-1}$. This experimental value of temperature coefficient of barrier height for the In/ $p$-Si Schottky contact is good in agreement with temperature coefficient value of $4.73 \times 10^{-4} \mathrm{eV} \mathrm{K}^{-1}$ for silicon [37].

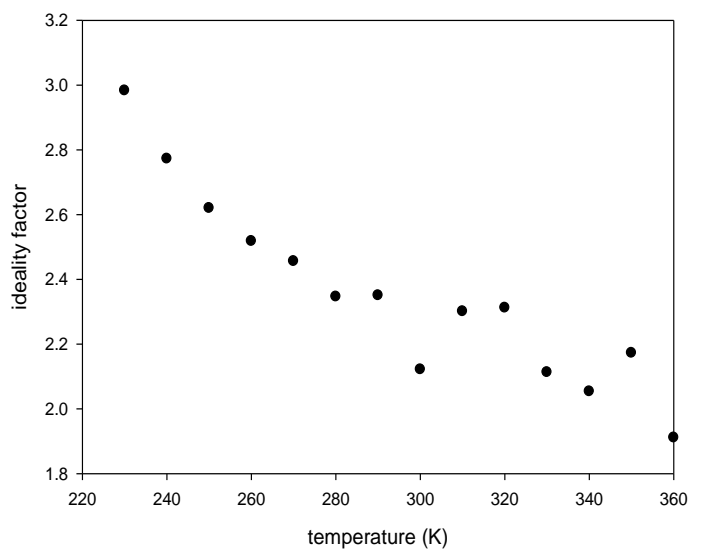

Fig. 2 - Ideality factor with temperature for $\mathrm{In} / p$-Si schottky contact

The Schmitsdorf, et al. [38] used Tung's theoretical approach that there is a linear relation between the apparent zero bias barrier height and ideality factors. The variation of the apparent barrier height versus the ideality factor is shown in Fig. 4. As shown in the figure, there is linear relationship between the apparent effective barrier heights and the ideality factor of the contacts that can be explained by lateral inhomogeneties of the barrier heights in Schottky contacts [39-42]. The extrapolation of the apparent barrier height versus the ideality factor plot to $n=1$ has given a homogeneous Schootky barrier height of approximately $1.11 \mathrm{eV}$. Thus, it can be said that the significant decrease of the zero bias barrier height and increase of the ideality factor towards decreasing temperature are possible caused by the barrier height inhomogeneties. It is seen to have good linearity and is a proof of applicability of the interfacial model [43]. The value of flat band barrier heights evaluated from here is found to be $1.07 \mathrm{eV}$.

To determine barrier height in another way by use of Richardson plot for reverse saturation current by taking natural logarithm of equation (2) rewritten as The Richardson constant is usually determinate from the intercept of $\ln \left(\frac{I_{s}}{T^{2}}\right) v s \frac{1}{T}$ plot. The conventional energy

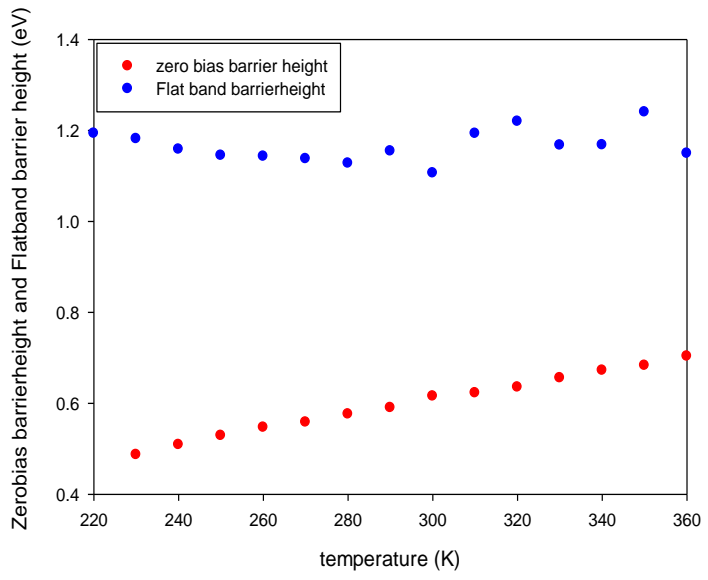

Fig. 3 - Zero bias barrier height and flat band barrier height for $\mathrm{In} / p$-Si schottky contact

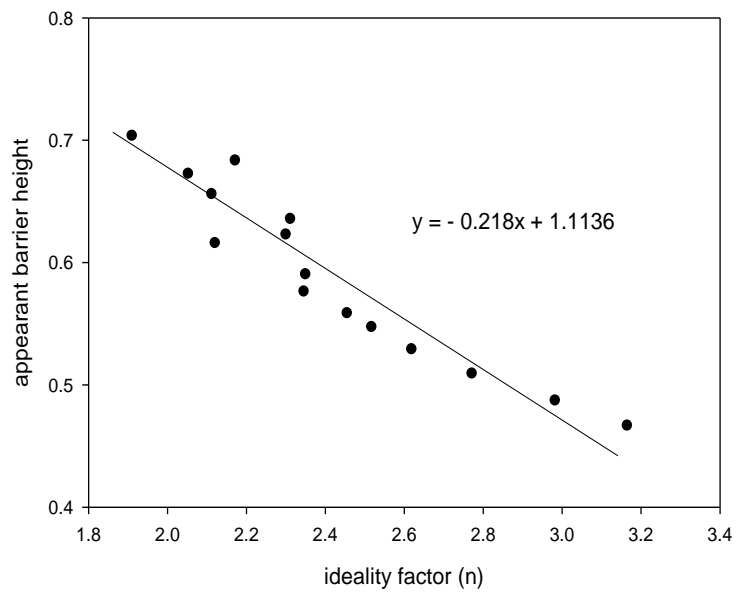

Fig. 4 - Linear variation of apparent barrier height vs ideality factor at different temperatures for $\mathrm{In} / p$-Si Schottky contact

$$
\ln \left(\frac{I_{s}}{T^{2}}\right)=\ln \left(A A^{*}\right)-\frac{q \phi_{b o}}{K T}
$$

variation of $\ln \left(\frac{I_{s}}{T^{2}}\right) v s \frac{1}{T}$ plot is found to be non linear in the temperature-range measured as shown in Fig. 5. However, the $n \ln \left(\frac{I_{s}}{T^{2}}\right) v s \frac{1}{T}$ gives a straight line as shown in Fig. 6 . The activation energy from the experimental data are shown in Fig. 5 gives $0.12 \mathrm{eV}$ and Richardson constant $A^{*}\left(2.07 \times 10^{-}\right.$ ${ }^{8} \mathrm{~A} / \mathrm{cm}^{2} \mathrm{~K}^{2}$ ) which is much lower than the known value of $\mathrm{p}$ type silicon $32 \mathrm{~A} / \mathrm{cm}^{2} \mathrm{~K}^{2}$. The deviation in the Richardson plots may be due to the spatial inhomogeneous barrier heights and potential fluctuations at the interface that consist of low and high barrier areas. [44-47]. In other words, the current of the diode will flow preferentially through the lower barriers in the potential distribution. Horvath [47] explained that the $A^{*}$ value obtained from the temperature dependence of the I-V characteristics may be affected by the lateral inhomogenity of 
the barrier. The plot of modified $n \ln \left(\frac{I_{s}}{T^{2}}\right) v s \frac{1}{T}$ gives an activation energy of $1.5 \mathrm{eV}$ and Richardson constant $25.58 \mathrm{~A} / \mathrm{cm}^{2} \mathrm{~K}^{2}$.

In real Schottky contact, the barrier heights vary over the contact area because of variations in the interfacial layer thickness and/or composition and also because of interfacial charges. For the correction the barrier height inhomogeneties have been obtained a modified value of the Richardson constant closer to the known value $32 \mathrm{~A} / \mathrm{cm}^{2} \mathrm{~K}^{2}$. The inhomogeneous barrier behaviour can be explained using an analytical potential fluctuation model [48-55]. The decrease in the barrier height with a decrease in temperature can be explained by the lateral distribution of barrier height if the barrier height has a Gaussian distribution analysis of the barrier height values with a mean value $\bar{\phi}_{b}$ and standard deviation $\sigma_{s}$ which can be given by $[54,55]$

$$
p\left(\phi_{b}\right)=\frac{1}{\sigma_{s} \sqrt{2 \pi}} \exp \left[\left(\frac{\phi_{b}-\overline{\phi_{b}}}{2 \sigma_{s}^{2}}\right)^{2}\right]
$$

Where $\frac{1}{\sigma_{s} \sqrt{2 \pi}}$ is the normalization constant of the Gaussian barrier height distribution. The total value I(V) across Schottky contact containing a barrier inhomogeneties can be expressed as

$$
I(V)=\int_{-\infty}^{\infty} I\left(\phi_{b}, V\right) P\left(\phi_{b}\right) d \phi_{b}
$$

Where $I\left(\phi_{b}, V\right)$ is the current at a bias $V$ for a barrier of height based on the ideal thermionic emissiondiffusion theory and $P\left(\phi_{b}\right)$ is the normalized distribution function giving the probability of accuracy for barrier height. Substituting Eq. (2) for $I\left(\phi_{b}, V\right)$ and Eq. (8) for $P\left(\phi_{b}\right)$ in Eq. (9), obtain the current $I(V)$ through the Schottky barrier at a forward bias $\mathrm{V}$ but with a modified barrier as [3]

$$
I(V)=I_{s} \exp \left(\frac{q V}{n_{a p} k T}\right)\left[1-\exp \left(-\frac{q V}{k T}\right)\right]
$$

With

$$
I_{s}=A A^{*} T^{2} \exp \left(-\frac{q \phi_{a p}}{k T}\right)
$$

Where $n_{a p}$ and $\phi_{a p}$ are the apparent ideality factor and the apparent barrier height respectively. With Gaussian distribution of barrier height at the interface due to homogeneities have shown that temperature variation at zero bias respectively is given by [56-58].

$$
\begin{gathered}
\phi_{a p}=\bar{\phi}_{b}(T=0)-\frac{q \sigma_{s o}^{2}}{2 k T} \\
\left(\frac{1}{n_{a p}}-1\right)=\rho_{2}-\frac{q \rho_{3}}{2 k T}
\end{gathered}
$$

It is believed that the mean value $\bar{\phi}_{b}$ and standard deviation $\sigma_{s}$ are linearly bias dependent of Gaussian parameter such that $\phi_{b}=\phi_{b o}+\rho_{2} V$ and $\sigma_{s}=\sigma_{s o}+\rho_{3} V$, where $\rho_{2}$ and $\rho_{3}$ are the voltage coefficients that may depend on temperature and they measure the voltage deformation of the barrier height distribution. Using the experimental data calculate $n_{a p}$ and $\phi_{b o}$ by Eqs. (3) and (4) at zero bias respectively, which should obey Eqs. (10) and (11). The plot of $\phi_{a p}$ versus $1 / T$ (Fig. 7) should be a straight line that gives $\phi_{b o}=1.06 \mathrm{eV}$ and $\sigma_{o}=0.16 \mathrm{~V}$ from the intercept and slope respectively. The standard deviation is a measure of the barrier inhomogenity. The lower value of $\sigma_{o}$ corresponds to more homogeneous barrier height [59].

The value of voltage coefficients $\rho_{2}$ and $\rho_{3}$ are obtained from the intercept and slope of the plot (Fig. 8) ( $\rho_{2}=1.11 \mathrm{~V}$ and $\rho_{3}=-0.017 \mathrm{~V}$ ). The linear behavior plot (Fig. 7 and 8 ) show that the ideality factor expresses the voltage deformation of the Gaussian distribution of the Schottky barrier contact. The value of standard deviation $\sigma_{o}$ from slope of this line is found to be $0.16 \mathrm{~V}$.

The conventional Richardson plot is now modified by combining Eqs. (11) with (12) as follows

$$
\ln \left(\frac{I_{s}}{T^{2}}\right)-\left(q^{2} \sigma_{0}^{2} / 2 k^{2} T^{2}\right)=\ln A A^{*}-\frac{q \phi_{b o}}{k T}
$$

The plot of a modified $\ln \left(\frac{I_{s}}{T^{2}}\right)-\left(q^{2} \sigma_{0}^{2} / 2 k^{2} T^{2}\right) v s \frac{1}{T}$ according to Eq. (13) should give a straight line with the slope directly yielding the mean $\phi_{b o}(T=0)$ and the intercept ( $\left.=\ln A A^{*}\right)$ at the ordinate determining Richardson constant $A^{*}$ for a given diode area $A$.

Fig. 9 shows this modified plot gives values of $\phi_{b o}(T=0)$ and $A^{*}$ as $1.17 \mathrm{eV}$ and $31.16 \mathrm{~A} / \mathrm{cm}^{2} \mathrm{~K}^{2}$ respectively, without using the temperature coefficient of the flat band barrier height. The value of $\phi_{b o}(T=0)=1.17 \mathrm{eV}$ from this plot is nearly same as the value of $\phi_{b o}(T=0)=1.06 \mathrm{eV}$ from the plot of $\phi_{a p} v s \frac{1}{T}$. However, Bhuiyan, Martinez and Esteve [60] give a new Richardson plot of $n \ln \left(\frac{I_{s}}{T^{2}}\right) v s \frac{1}{T}$ for non ideal Schottky contacts and it gives a good straight line with $\phi_{b o}=1.56 \mathrm{eV}$ (Fig. 5). 


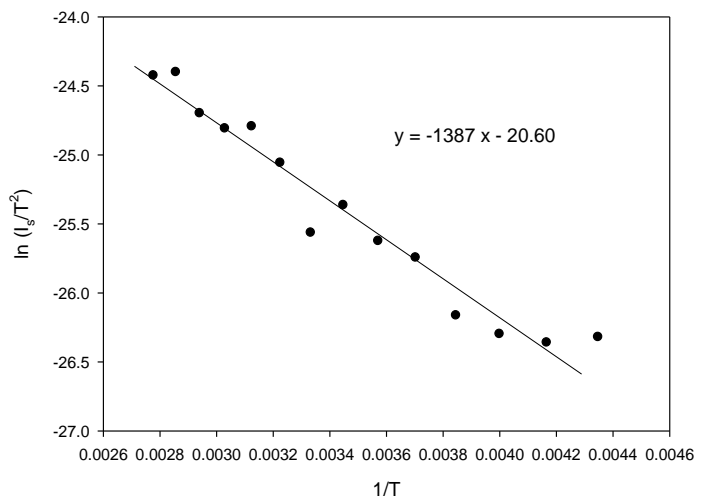

Fig. 5 - Richardson plot of the $\ln \left(\frac{I_{s}}{T^{2}}\right) v s \frac{1}{T}$ for $\operatorname{In} / p-\mathrm{Si}$ Schottky contact

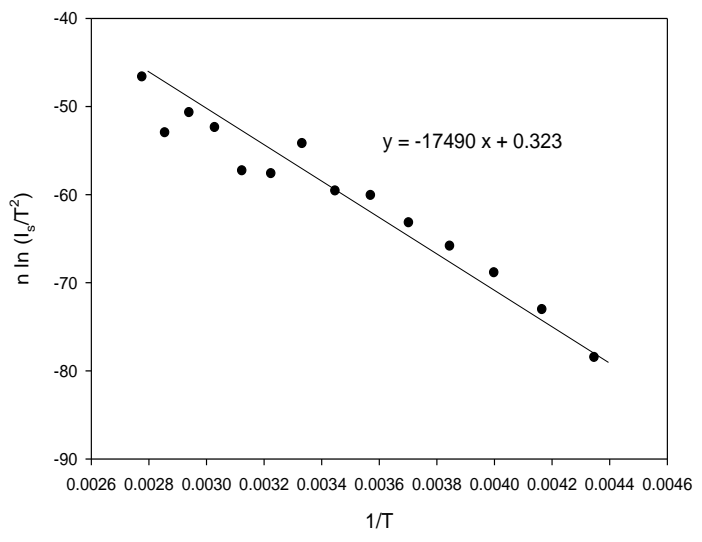

Fig. 6 - The modified Richardson plot $n \ln \left(\frac{I_{s}}{T^{2}}\right) v s \frac{1}{T}$ for In/p-Si Schottky contact

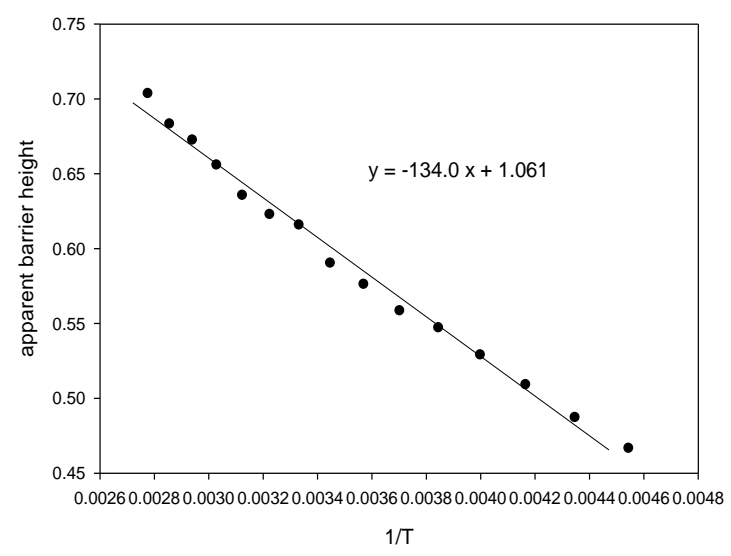

Fig. 7 - Apparent barrier height vs $1 / T$ for $\mathrm{In} / p$-Si Schottky contact

It is found that the barrier height has a value of around $1.06 \mathrm{eV}$ from the plot of $\phi_{a p} v s \frac{1}{T}$ which is compared with the flat band barrier height $1.07 \mathrm{eV}$ and the barrier height obtained from the modified
Richardson plot $1.17 \mathrm{eV}$ and the standard deviation in barrier height is $0.16 \mathrm{~V}$. Thus, the conformity to be quite satisfactory.

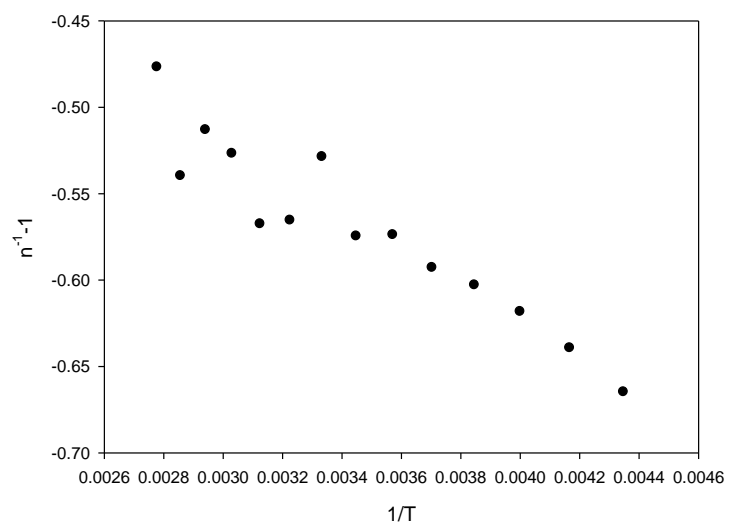

Fig. 8 - Variation $\left(n^{-1}-1\right) v s \frac{1}{T}$ for In/p-Si Schottky contact

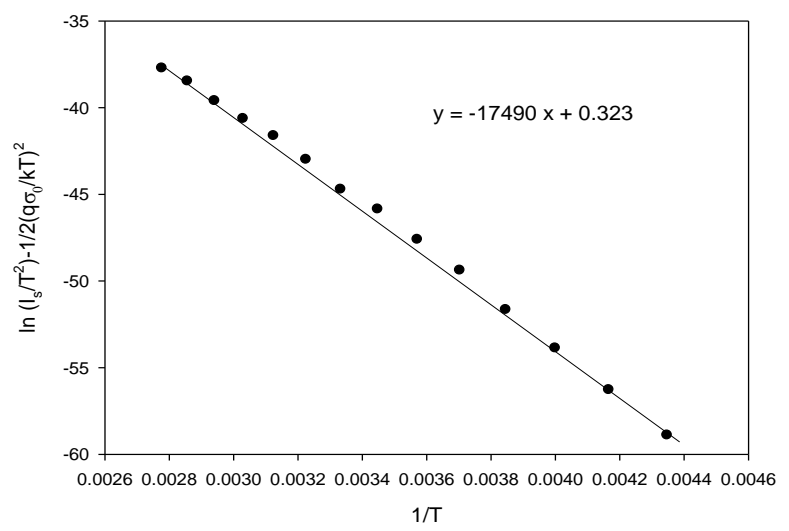

Fig. 9 - The modified Richardson plot $\ln \left(\frac{I_{s}}{T^{2}}\right)-\frac{1}{2}\left(\frac{q \sigma_{o}}{k T}\right)^{2} v s \frac{1}{T}$ for In- $p \mathrm{Si}$ Schottky contact according to Gaussian distribution of barrier heights

\section{CONCLUSION}

Evaluation of non ideal Schottky contact is very complex. The I-V characteristics of In/p-Si Schottky contact were measured over the temperature range of 220-360 K. It can be interpreted on the basis of the TE theory with Gaussian distribution of the barrier height of $\phi_{b o}(T=0)=1.17 \mathrm{eV}$ and standard deviation $\sigma_{o}$ is found to be $0.16 \mathrm{~V}$. The lower value $\sigma_{o}$ corresponds to more homogenous barrier height. In addition, the inhomogenity and potential fluctuations may be occurring as a result of inhomogeneties in the composition of interfacial oxide layer or thickness and non uniformity of interfacial charges. Furthermore, the experimental results of $\phi_{a p}$ and $n_{a p}$ fit very well for the theoretical equation related to the Gaussian distribution of $\phi_{a p}$ and $n_{a p}$. Again the $\ln \left(\frac{I_{s}}{T^{2}}\right) v s \frac{1}{T}$ plot gives an unfair effective Richardson 
constant, but used Richardson Plot of $n(T) \ln \left(\frac{I_{S}}{T^{2}}\right) v s \frac{1}{T}$ and modified Richardson plot obtained $A^{*}=25.58 \mathrm{~A} / \mathrm{cm}^{2}$ $\mathrm{K}^{2}$ and $31.16 \mathrm{~A} / \mathrm{cm}^{2} \mathrm{~K}^{2}$ respectively Thus, modified Richardson plot using Gaussian distribution of the barrier height is very nearer to the theoretical value $32 \mathrm{~A} / \mathrm{cm}^{2} \mathrm{~K}^{2}$ of holes in $p$-type silicon.

\section{REFERENCE}

1. E.H. Rhoderick, R.H. Williams, Metal-Semiconductor contacts (Clarendon Press: Oxford: 1988).

2. R.T. Tung, Appl. Phys. Rev. 1, 0111304 (2014).

3. K Ejderha, N. Yildirim, A. Turat, Superlattice. Microstr. 47, 241 (2010).

4. S. Shankar Niak, V Rajgopal Reddy, Superlattice. Microstr. 48, 330 (2010).

5. O. Gullu, A. Turat, J. Alloy. Compd. 509, 571 (2011).

6. M.K. Hudait, S.B. Krupanidhi, Solid State Electron. 44, 1087 (2000).

7. M. Biber, M. Cakar, A. Turut, J. Mater. Sci.-Mater. Elect. 12, 575 (2001).

8. H. Kanbur, S. Altindal, A. Tataroglu, Appl. Surf. Sci. 252, 1732 (2005).

9. S. Karatas, S. Alt1ndal, A. Turat, M. Cakar, Physica B 392, 43 (2007).

10. S.K. Cheung, N.W. Cheung, Appl. Phys. Lett. 49, 85 (1986).

11. A. Turat, M. Saglam, Physica B 179, 285 (1992).

12. M.K. Hudait, S.P. Venkateswarlu, S.B. Krupanidhi, Solid State Electron. 45, 133 (2001).

13. J.P. Sullivan, R.T. Tung, M.R. Pinto, J. Appl. Phys. 70, 7403 (1991).

14. A. Gumus, A. Turit, N. Yalcin, J. Appl. Phys. 91, 245 (2002).

15. S. Altindal, S. Karadeniz, N. Tugluogiu, A. Tataroglu, Solid State Electron. 47, 1847 (2003).

16. S. Karatas, S. Altindal, M. Cakar, Physica B 357, 386 (2005).

17. M. Ozer, D.E. Yildiz, S. Alt1ndal, M.M. Bulbul, Solid State Electron. 51, 941 (2007).

18. M.K. Hudait, S.P. Venkateswarlu, S.B. Krupanidhi, Solid State Electron. 45, 133 (2001).

19. H. Korkuta, N. Yildırıma, A. Turut, H. Dogan, Mater. Sci. Eng. B 157, 48 (2009).

20. H. Altuntas, S. Altındal, H. Shtrikman, S. Özçelik, Microelectron. Reliability 49, 904 (2009).

21. M. Sharma, S.K. Tripathi, J. Appl. Phys. 112, 024521 (2012).

22. S. Chand, Semicond. Sci. Technol. 17, L36 (2002).

23. H. Cetin, B. Sahin, E. Ayyildiz, A. Turat, Semicond. Sci. Technol. 19, 1113 (2004).

24. M.E. Aydin, O. Gullu, N. Yild1r1m, Physica B 403, 131 (2008).

25. M. Saglm, A. Ates, B. Guzeldir, A. Astam, M.A. Y1ld1r1m, J. Alloy. Compd. 480, 962 (2009).

26. M. Mamor, J. Phys. Condens. Matt. 21, 335802 (2009).

27. I1bi1ge Dokme, Semesettin Altindal, M.M. Bulbul, Appl. Surf. Sci. 252, 7749 (2006).

28. W. Mtangi, F.D. Auret, C. Nyamhere, P.J. Janse van Rensburg, M. Diale, A. Chawanda, Physica B 404, 1092 (2009).

29. B.P. Modi, J. Nano- Electron. Phys. 3 No 1, 680 (2011).

\section{ACKNOWLEDGMENT}

We thank to Dr. K.D. Patel and Prof. R. Srivastava, Department of Physics, Sardar Patel University, Vallabh Vidyanagar for meaningful discussion with this paper. These acknowledged with a deep sense of gratitude.

30. M.M. Heyns, S. Verhaverbeke, M. Meuris, P.W. Merteus, H. Schmidt, M. Kubota, A. Phillpresian, K. Dillenbech, D. Grat, A. Schnegg, R. DeBlank, Mater. Res. Soc. Symp. Proc. 315, 35 (1993).

31. S.M. Sze, Physics of Semiconductor Devices, 2nd Ed. (New York: Wiley Eastern: 1993).

32. S. Ashok, J.M. Borrego, R.J. Gutmann, Solid State Electron. 22, 621 (1979).

33. S. Duman, Semicond. Sci. Technol. 23, 075042 (2008).

34. S. Hardikar, M.K. Hudait, P. Modak, S.B. Krupanidhi, N. Padha, Appl. Phys. A 68, 49 (1999).

35. A. Gumus, A. Turat, N. Yalcin, J. Appl. Phys. 91, 245 (2002).

36. L.F. Wagner, R.W. Young, A. Sugerman, IEEE Electron. Dev. Lett. 4 No 4, 320 (1983).

37. H.C. Card, E.H. Rhoderick, J. Phys. D Appl. Phys. 4, 1589 (1971).

38. R.F. Schmitsdorf, T.U. Kampen, W. Mönch, J. Vac. Sci. Technol. B 15, 1221 (1997).

39. R.T. Tung, Phys. Rev. B 45, 1509 (1992).

40. S. Sankar Nair, V. Rajgopal Reddy, Adv. Mat. Lett. 3 No 3, 188 (2012).

41. W. Monch, J. Vac. Technol. B 17, 1867 (1999).

42. C. Temric, B. Bati, M. Saglam, A. Turut, Appl. Surf. Sci. 172, 1 (2001).

43. R.F. Schmitsdorf, T.U. Kampen, W. Monch, Surf. Sci. 324, 249 (1995).

44. J.H. Werner, H.H. Guttler, J. Appl. Phys. 69, 1522 (1991).

45. Y.P. Song, R.L. Van Merihaeghe, W.H. Lafiere, F. Cardon, Solid State Electron. 29, 633 (1986).

46. S. Karatas, S. Alt1ndal, A. Turat, A. Ozmen, Appl. Surf. Sci. 217, 250 (2003).

47. Zs. Horvarth, Solid State Electron. 39, 176 (1996).

48. M.K. Hudait, P. Venkateswarlu, S.B. Krupanidhi, Solid-State Electron. 45, 133 (2001).

49. S. Chand, Semicond. Sci. Technol. 19, 82 (2004).

50. S. Zhu, R.L. Van Meirhaeghe, C. Detavernier, G.P. Ru, B.Z. Li, F. Cardon, Solid-State Commun. 112, 611 (1999).

51. Ş. Altındal, S. Karadeniz, N. Tuğluoğlu, A. Tataroğlu, SolidState Electron. 47, 1847 (2003).

52. S. Zeyrek, Ş. Altındal, H. Yüzer, M.M. Bülbül, Appl. Surf. Sci. 252, 2999 (2006).

53. S. Zhu, R.L. Van Meirhaeghe, C. Detavernier, F. Cardon, G.P. Ru, X.P. Qu, B.Z. Li, Solid-State Elecron. 44, 663 (2000).

54. O.S. Anilturkand, R. Turan, Solid-State Electron. 44, 41 (2000). 55. S. Bandyopadhaya, A. Bhattacharya Andd, S.K. Sen, J. Appl. Phys. 85, 3671 (1999).

56. J.H. Werner, H.H. Guttler, Phys. Scr. T39, 258 (1991).

57. S. Karats, S. Altidnal, A. Turut, A. Ozmen, Appl. Surf. Sci. 217, 250 (2003).

58. A. Gumus, A. Turut, N. Yalcin, J. Appl. Phys. 91, 245 (2002).

59. R.T. Tung, Mater. Sci. Eng. $R$ 35, 1 (2001).

60. A.S. Bhuiyan, A. Martinez, D. Esteve, Thin Solid Films 161, 93 (1988). 